\title{
ARTIGOS
}

\section{EVOLUÇÃO DA CARDIOPATIA EXPERIMENTALMENTE INDUZIDA EM COELHOS INFECTADOS COM TRYPANOSOMA CRUZI}

\author{
Florêncio Figueiredo*, Marcos A. Rossi ${ }^{\star}$ e Ricardo R. Santos*^
}

\begin{abstract}
Coelhos jovens de ambos os sexos (1-2 meses de idade), outbred, inoculados com tripomastigotas da cepa Colômbia de Trypanosoma cruzi desenvolveram lesões cardíacas, macro e microscópicas, além de características parasitológicas e imunológicas, muito semelhantes às observadas na doença de Chagas humana, tanto na fase aguda como na fase crônica. Na fase aguda a sindrome cardiaca caracteriza-se macroscopicamente por discreta cardiomegalia, com dilatação de câmaras direitas, $e$ miscroscopicamente por miocardite focal pouco acentuada; na fase crônica, por cardiomegalia moderada ou acentuada, com hipertrofia e dilatação de câmaras $e$ adelgaçamento da ponta (aneurisma apical), predominantemente do ventriculo esquerdo, e por miocardite focal, cơm áreas de necrose miocitolitica e degeneração de miocélulas, associadas a infiltrado inflamatório, principalmente composto de linfócitos, e fibrose intersticial. Devido à reprodução de aspectos da doença cardíaca chagásica humana em tempo relativamente curto, à simplicidade, à disponibilidade para múltiplos pesquisadores e ao baixo custo, o modelo representado pelo coelho constitui uma alternativa para estudos dos mecanismos, patologia e tratamento da cardiopatia chagásica.
\end{abstract}

Palavras chave: Trypanosoma cruzi. Coelho. Cardiopatia chagásica. Doença de Chagas. Modelo experimental.

A doença de Chagas, constitui um dos mais importantes problemas de saúde pública no paises latino-americanos ${ }^{29}$. A doença é caracterizada por três fases: aguda, latente e crónical 1617 . O mais importante envolvimento visceral è o do coração. $\mathrm{Na}$ fase aguda, o grau de envolvimento miocárdico varia desde formas leves, assintomáticas ou oligossintomáticas, até formas graves, eventualmente fatais; estas formas graves são infreqüentes e constituem apenas 3 $-10 \%$ dos casos ${ }^{17}$. $\mathrm{Na}$ fase crônica, nos estágios iniciais, o paciente pode ser assintomático ou apresentar sintomas relacionados a distúrbios de ritmo; nos estágios intermediários, as manifestações clínicas persistem ou se intensificam, e um aumento do coração, de grau leve a moderado, pode ser detectado;

\footnotetext{
* Departamento de Patologia, Faculdade de Medicina de Ribeirão Preto, Universidade de São Paulo; ** Departamento de Parasitologia, Microbiologia e Imunologia, Faculdade de Medicina de Ribeirão Preto, Universidade de São Paulo. Trabalho financiado parcialmente pela FAPESP, CNPq e FIPEC.

Endereço para correspondência: Dr. Florêncio Figueiredo, Departamento de Patologia, Faculdade de Medicina de Ribeirão Preto da Universidade de São Paulo, 14100 Ribeirão Preto, SP, Brasil.
}

Recebido para publicação em 27/9/84. nos estágios finais, há acentuado aumento do coração com grave insuficiência cardíaca congestiva, fenómenos tromboembólicos e arritmias graves. A morte repentina representa um perigo constante em qualquer estágio da doença. A fase latente é o periodo intermediário que separa as fases aguda e crônica, usualmente de longa duração (10 - 20 anos), pouco se conhecendo sobre suas manifestações clínicopatológicas.

A patologia reflete a importância do envolvimento cardiaco na doença de Chagas 2,13 . Na fase aguda, o coração é globoso e flácido; microscopicamente observam-se focos de necrose miocitolitica e degeneração miocelular com intenso infiltrado inflamatório mononuclear associados a fenómenos exsudativos e parasitismo de miofibras. Na fase crônica, a cardiopatia é polimorfa, com graus variáveis de hipertrofia e dilatação, apresentando ou não aneurisma apical; microscopicamente observa-se um infiltrado inflamatório focal ou difuso, focos de necrose miocitolítica e degeneração de células miocárdicas, fibrose intersticial de grau variável e raras fibras com parasitos intracelulares.

Vários mecanismos têm sido considerados como implicados na patogênese da cardiopatia cha- 
Figueiredo $F$, Rossi MA, Santos RR. Evolução da cardiopatia experimentalmente induzida em coelhos infectados com Trypanosoma cruzi Revista da Sociedade Brasileira de Medicina Tropical 18: 133-141, Jul-Set, 1985

gásica, tais como os de natureza imunológica 8202324 hipoxêmica 122128 e neurogénica 13 . Todavia, a patogénese dessa cardiopatia permanece não esclarecida.

No presente trabalho descrevemos a evolução, do ponto de vista anatomopatológico, da cardiopatia experimentalmente induzida em coelhos infectados com $T$. cruzi. Estudos clínicos, patológicos, parasitológicos e imunológicos foram relatados anteriormente 182425 . O presente estudo estende e aprofunda a descrição dos achados patológicos.

\section{MATERIAL E MÉTODOS}

Vinte e cinco coelhos outbred da raça Nova Zelândia, de ambos os sexos, com $1-2$ meses de idade, foram inoculados por via subcutânea com $1 \times 10^{6}$ formas tripomastigotas $/ \mathrm{kg}$ de peso corporal da cepa Colômbia de $T$. cruz $i^{y}$, obtidas por punção cardíaca de camundongos em pico de parasitemia. Quinze animais-controle foram injetados com solução salina em vez de cepa Colômbia de $T$. cruzi.

Os animais foram mantidos em gaiolas individuais sob condições ambientais controladas. A parasitemia foi avaliada pelo teste do xenodiagnósticolu. Os coelhos foram sangrados periodicamente e os soros estocados a $-20^{\circ} \mathrm{C}$ para posterior pesquisa de anticorpos contra $T$. cruzi pelos métodos de imunofluorescência indireta e hemaglutinação passiva 45 .

Para a realização do estudo anatomopatológico foram sacrificados cinco animais inoculados e três animais-controle aos 30,60,120,240 e 540 dias após a inoculação. $O$ coração foi rapidamente removido, lavado em solução gelada de $\mathrm{NaCl}$ a $0,9 \%$ e fixado por inteiro em formalina neutra a $10 \%$. Todos os corações foram seccionados do ápice para a base em duas metades, uma anterior e outra posterior e avaliados macroscopicamente; foram colhidos fragmentos dos átrios e dos ventrículos. Após inclusão em parafina foram obtidas secções de $6 \mu \mathrm{m}$ de espessura, coradas com hematoxilina-eosina e pelo método tricrômico de Cason e examinadas ao microscópio óptico. Para o estudo ultra-estrutural, pequenos fragmentos da base e das proximidades da ponta de quatro corações de coelhos infectados (dois com 120 e dois com 240 dias) e de dois respectivos controles, foram fixados em aldeído glutárico a $2,5 \%$ em tampão de fosfato $(\mathrm{pH}$ 7,3) por duas horas, pós-fixados em tetróxido de ósmio a $1 \%$ em tampão de fosfato, desidratados em concentrações ascendentes de acetona e incluidos em resina de epóxi (Araldite). Secções ultrafinas foram obtidas em ultramicrótono Sorvall MT-5000, duplamente coradas com citrato de chumbo e acetato de uranila e examinadas em microscópio eletrônico Zeiss em $109 \mathrm{a}$ $80 \mathrm{kV}$.

\section{RESULTADOS}

Todos os animais inoculados com $T$. cruzi apresentaram niveis de parasitemia detectados pelo xenodiagnóstico (Fig. 1). No 15\% dia pós-infecção a parasitemia atingiu um pico, quando $100 \%$ dos barbeiros examinados estavam positivos. Posteriormente o percentual de triatomíneos infectados decresceu paulatinamente, atingindo niveis intermediários que oscilaram entre 30 e $40 \%$ de positividade nos $30 \%$ e 40 . dias após a inoculação; após 60 dias apenas $10 \%$ dos barbeiros estavam positivos, enquanto com $90 \mathrm{ou}$ mais dias todos os animais tiveram xenodiagnósticos negativos.

O percentual de coelhos infectados com anticorpos humorais específicos contra $T$. cruzi $\dot{e}$ mostrado na Figura 2. No 10 \% dia após a inoculação,

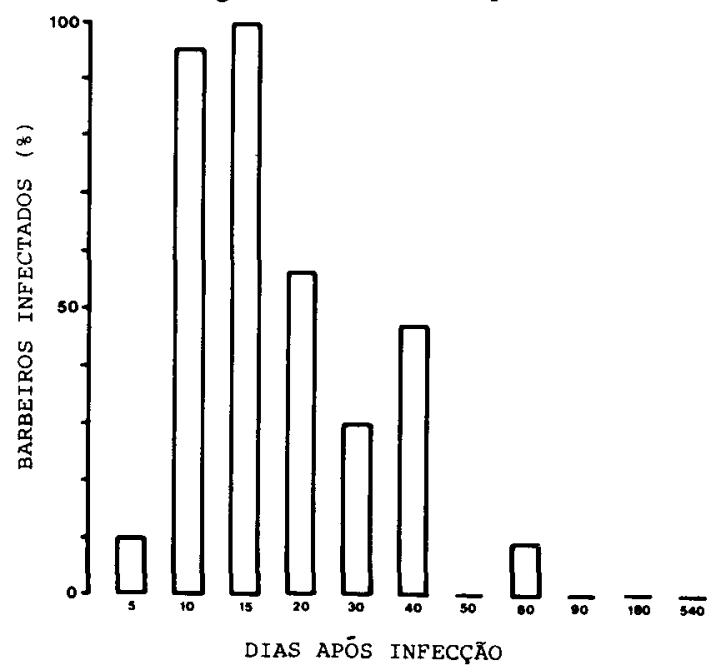

Figura 1 - Parasitemia demonstrada pelo xenodiagnóstico em coelhos inoculados com a cepa Colombia de $\mathrm{T}$. cruzi (parasitemia $=$ número de $\mathrm{D}$. maximus infectados com $\mathrm{T}$. cruzi/número total de insetos usados $x$ 100).

COELHOS COM ANTICORPOS CONTRA T. oruzi (\%)
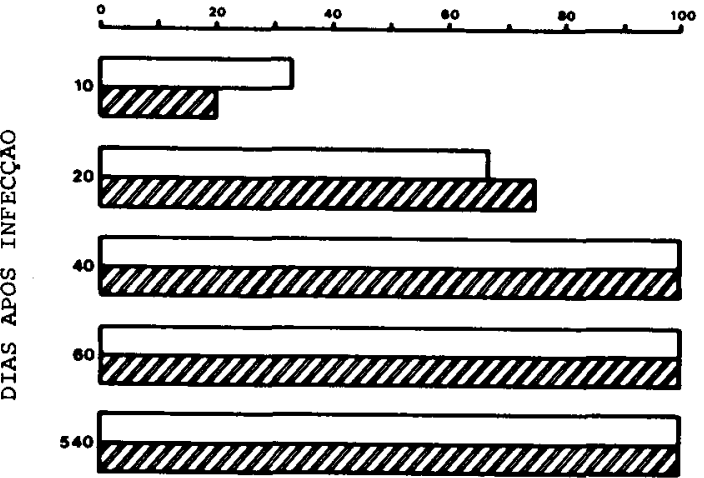

Figura 2-Pesquisa de anticorpos circulantes contra T. cruzi no soro de coelhos inoculados, pelas técnicas de imunoflorescência indireta ( $\square$ ) e de hemaglutinação passiva (R). 
Figueiredo $F$, Rossi MA, Santos RR. Evoluçäo da cardiopatia experimentalmente induzida em coelhos infectados com Trypanosoma cruzi. Revista da Sociedade Brasileira de Medicina Tropical 18: 133-141, Jul-Set, 1985

$33,3 \%$ e $20 \%$ dos animais apresentaram títulos de anticorpos detectados pelas técnicas de imunofluorescência e hemaglutinação, respectivamente. No 20 \% dia, essas taxas se elevaram para $66,6 \%$ e $75 \%$, respectivamente. Depois de 40 dias pós-infecção todos os animais apresentaram anticorpos detectados por ambas as técnicas.

Até 60 dias após a inoculação de $T$. cruzi os coraçōes de quatro coelhos mostravam-se idênticos aos dos controles; os demais apresentavam-se flácidos, com miocárdio congesto e dilatação de câmaras direitas. Alterações macroscópicas importantes foram

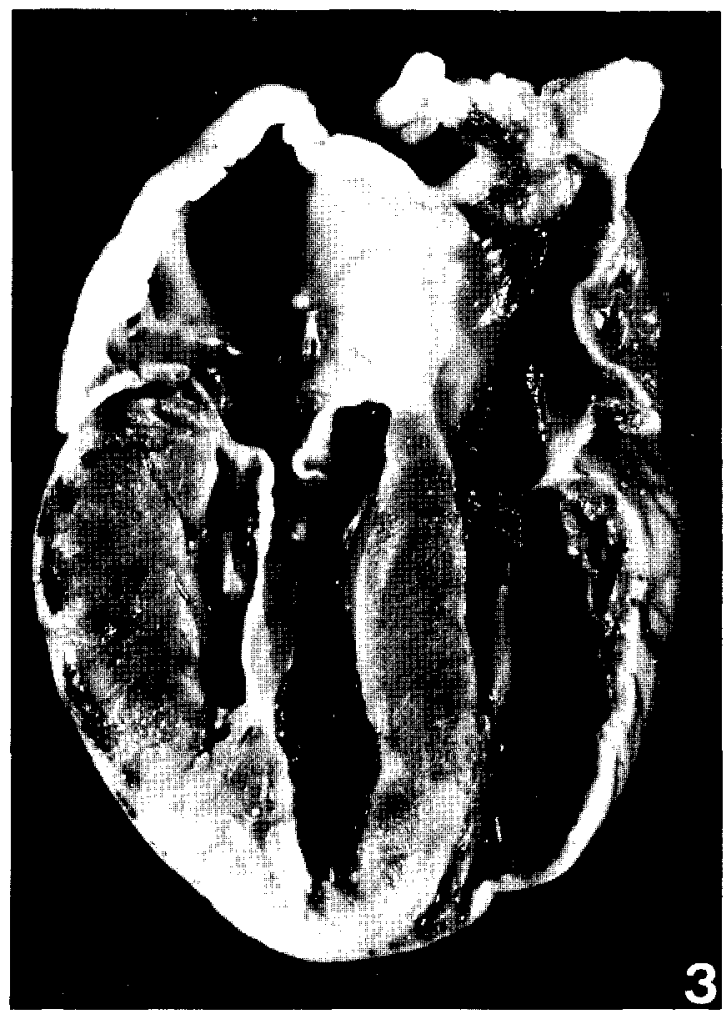

Figura 3-Coração de coelho com 540 dias de infecção pelo T. cruzi, apresentando hipertrofia e dilatacão de câmaras: $2,2 x$.

O exame histopatológico do miocárdio de coelhos infectados revelou alterações focais cuja intensidade era proporcional ao tempo de infecçăo. Nos animais sacrificados com 30 dias observou-se um quadro de miocardite focal discreta, com dissociação edematosa de miofibras, focos de necrose miocitolitica e degeneração e infiltrado mononuclear. Após 60 dias, a miocardite era mais intensa, com áreas disseminadas de necrose miocitolitica e alterações degenerativas de miocélulas; miofibras atróficas ao lado de outras observadas a partir de 120 . dia após a inoculação. Dos 15 corações examinados de animais com 120 ou mais dias de infecção, oito $(53,3 \%)$ apresentavam cardiomegalia com graus variados de dilatação e hipertrofia das câmaras (Figs. 3 e 4) e abaulamento do cone da pulmonar. Adelgaçamento da ponta do ventriculo esquerdo (aneurisma apical) foi detectado em quatro (26,6\%) coraçōes (Fig. 4), um dos quais também apresentava adelgaçamento da ponta do ventrículo direito. Outro achado freqüente foi a fibrose miocárdica, observada em oito $(53,3 \%)$ corações, de intensidade proporcional ao tempo de infecção.

(Figs. 3 e 4)

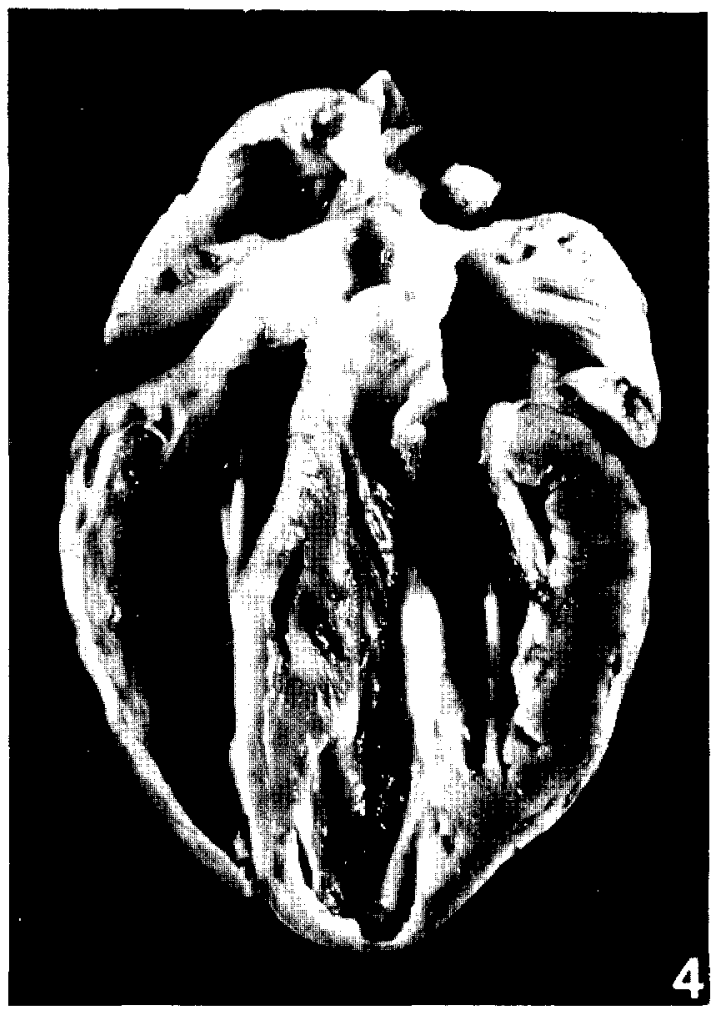

Figura 4-Coração de coelho com 240 dias de infecção pelo T. cruzi, apresentando dilatação de câmaras, hipertrofia e aneurisma apical (ventriculo esquerdo). $2,2 x$.

hipertrofiadas puderam ser vistas, além de um infiltrado celular mononuclear intenso. As Figuras 5 e 6 mostram o miocárdio de coelhos com 120 dias de infecção. A fibrose intersticial variava desde o padrão perivascular e discreto até o comprometimento de extensas áreas do miocárdio (Figs. 7 e 8).

As alterações ultra-estruturais do miocárdio de animais com 120 e 240 dias de infecção variavam de 


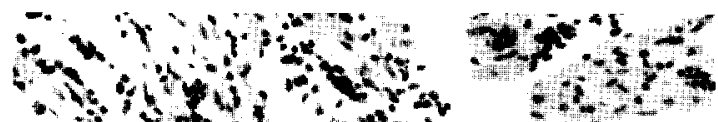

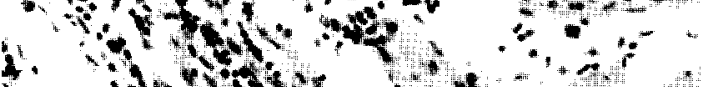

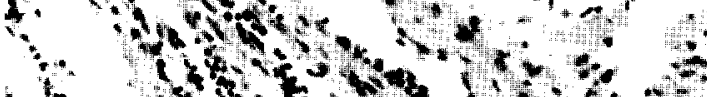
tot

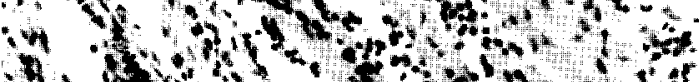

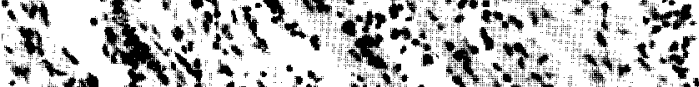

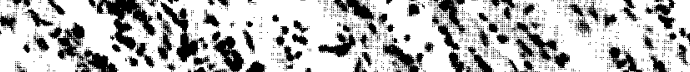

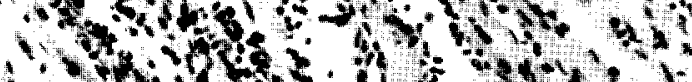

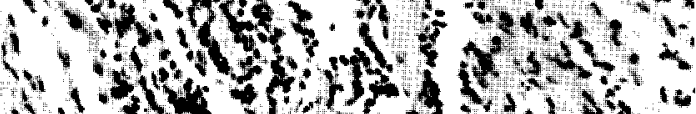

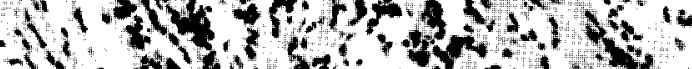

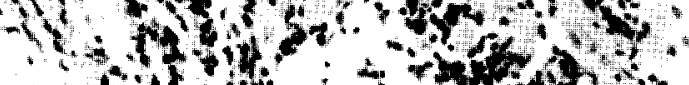

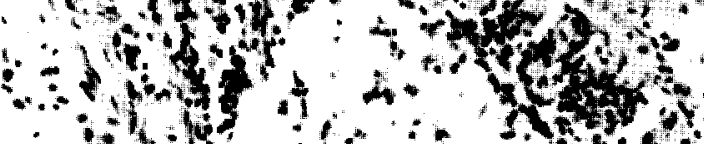

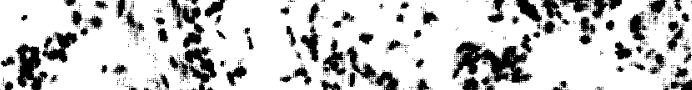

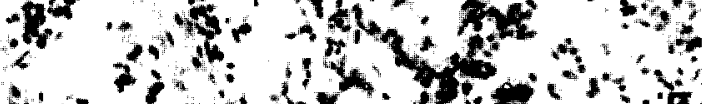

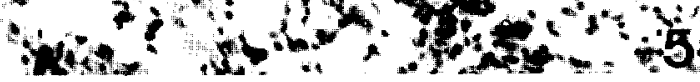

Figura 5-Miocárdio de coelho com 120 dias de infecção pelo $\mathrm{T}$. cruzi Necrose miocitolítica e degeneração miocelular. Resposta inflamatória mono nuclear. Dissociação de miofibras. H.E. 170x.

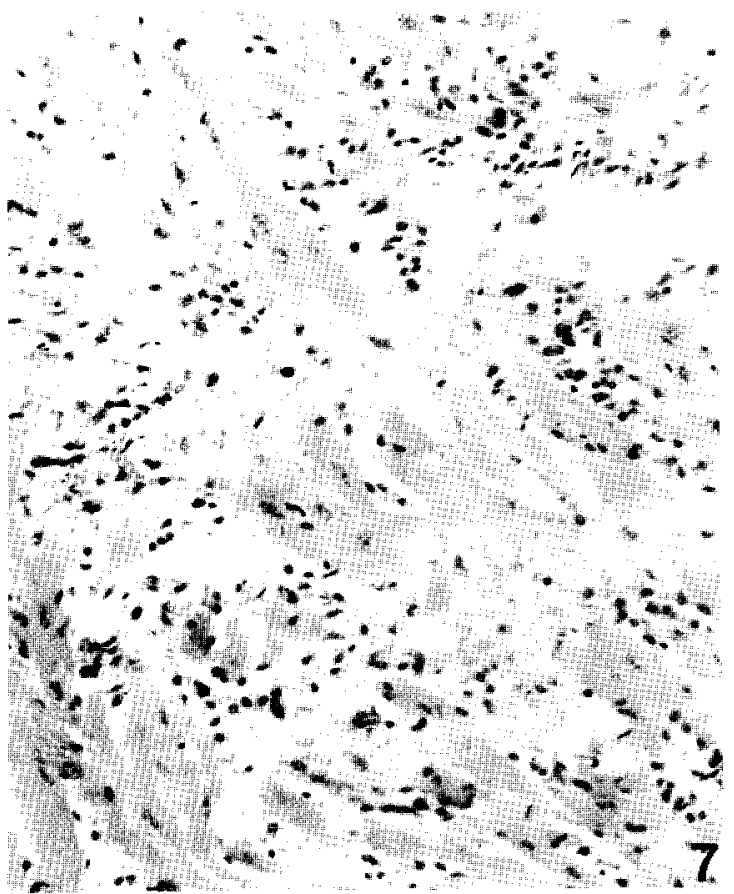

Figura 7 - Miocárdio de coelho com 240 dias de infecção. Fibrose intersticial difusa acentuada associada a infiltrado mononuclear. H.E. $170 x$.

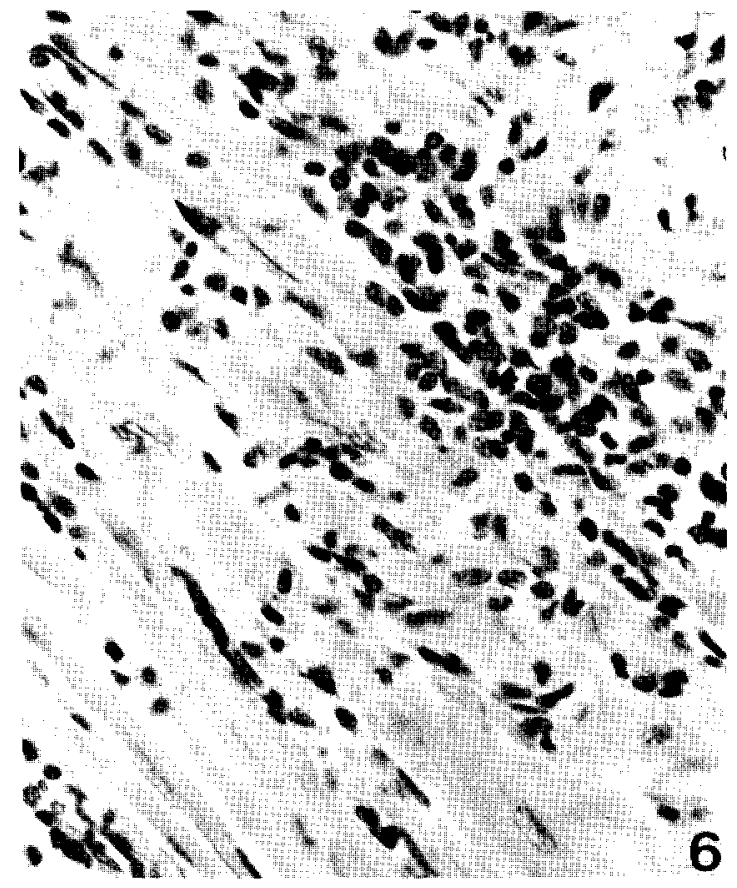

Figura 6-Miocárdio de coelho com 120 dias de infecção. Foco de necrose miocitolítica e degeneração miocelular. Infiltrado intersticial mononuclear H.E. $430 x$

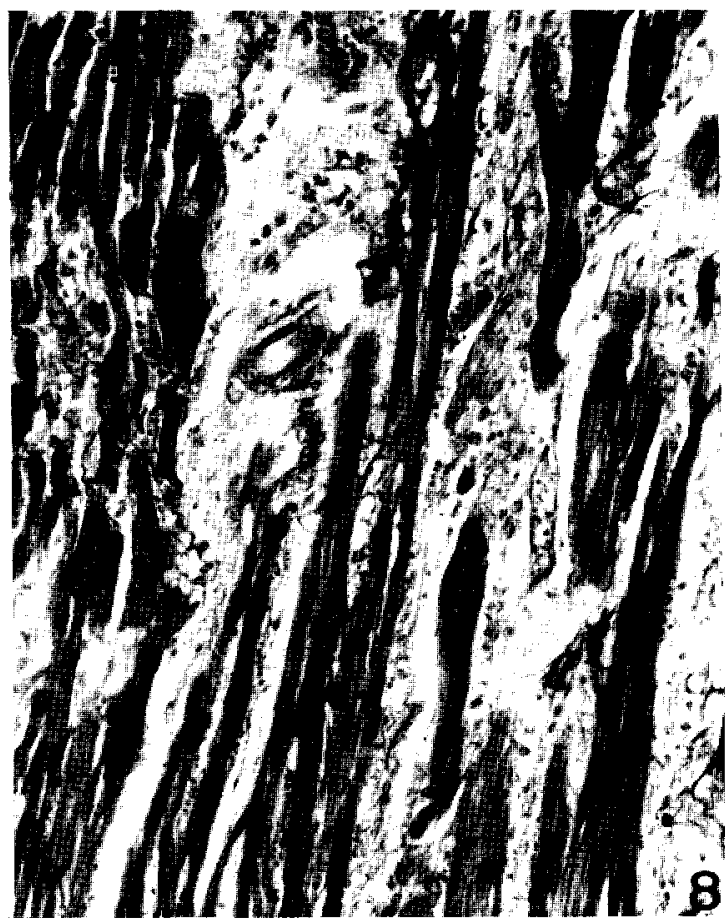

Figura 8-Miocárdio de coelho com 240 dias de infecção. Fibrose intersticial. Infiltrado mononuclear. Lise e degeneração de miofibras. Tricrômico de Cason, 170x. 
Figueiredo F, Rossi MA, Santos RR. Evoluçāo da cardiopatia experimentalmente induzida em coelhos infectados com Trypanosoma cruzi. Revista da Sociedade Brasileira de Medicina Tropical 18: 133-141, Jul-Set, 1985

uma área para outra e de um aspecto normal à completa dissociação das fibras miocárdicas. Em áreas discretas e moderadamente lesadas as miofibras mostravam-se desorganizadas, com focos de lise. Além disso havia edema intermiofibrilar, com formação de vacúolos intracitoplasmáticos. As mitocôndrias mostravam-se tumefeitas, com desorganização e ruptura de cristas e diminuição da densidade da matriz mitocondrial. Um aparente aumento do número

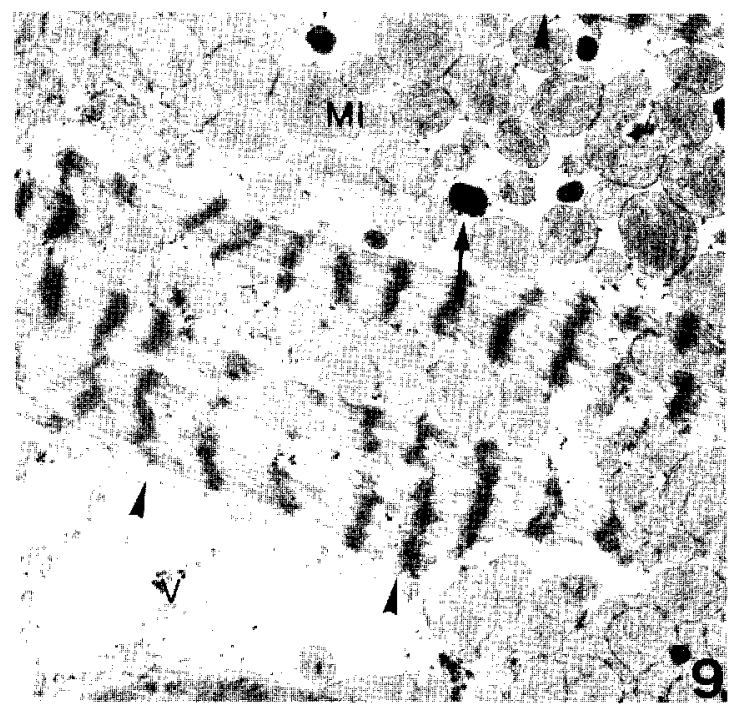

Figura 9-Eletromicrografia (EM): Miofibrilas hipercontraidas com ruptura e perda de miojilamentos (pontas de flechas). Edema intracelular $e$ vacuolização (V). Presença de número aumentado de corpúsculos eletrodensos (peroxisomas?) (flechas). Mitocondriose (MI). 7000x.

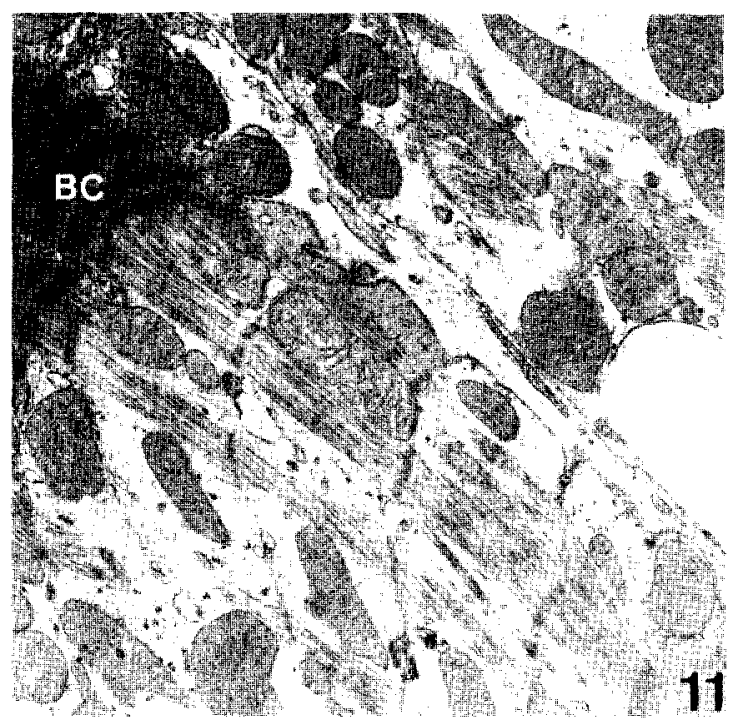

Figura 11-EM: Edema intermiofibrilar(*). Lise de miofilamentos. Bandas de contratura (BC). 10560x. de mitocóndrias (mitocondriose) foi também evidenciado. Freqüentemente as miocélulas estavam hipercontraidas, com formação de bandas anómalas de contratura. $\mathrm{O}$ espaço intersticial estava ampliado devido a fluido de edema e infiltração celular por fibroblastos ativados com deposição de fibras colágenas e discreto infiltrado constituido predominantemente por linfócitos (Fig. 9 -16).

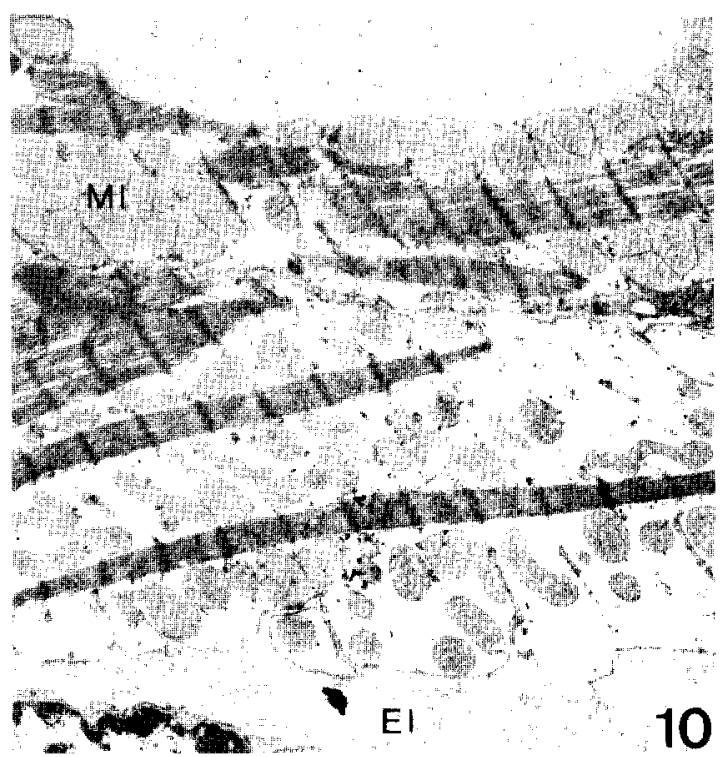

Figura 10-EM: Edema intracelular. Vacúolo intracitoplasmático (V). Mitocondriose (MI). EI, espaço intersticial. 5200x.

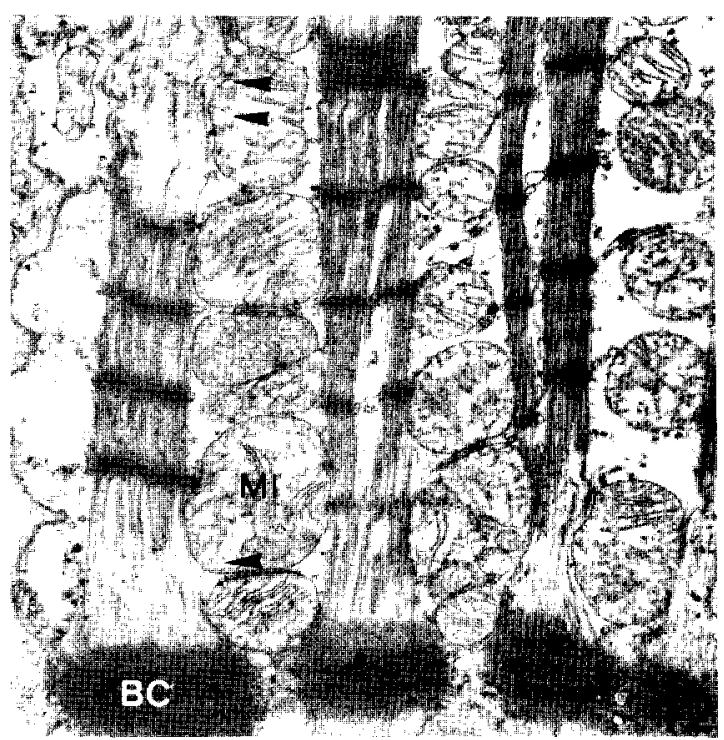

Figura 12 - EM: Tumefação mitocondrial (MI), com aclaramento de matriz e ruptura de cristas. Bandas de contratura $(B C)$. Ruptura de miofilamentos (pontas de flechas). Edema intermiofibrilar. $10560 x$ 
Figueiredo F, Rossi MA, Santos RR. Evolução da cardiopatia experimentalmente induzida em coelhos infectados com Trypanosoma cruzi Revista da Sociedade Brasileira de Medicina Tropical 18: 133-141, Jul-Set, 1985

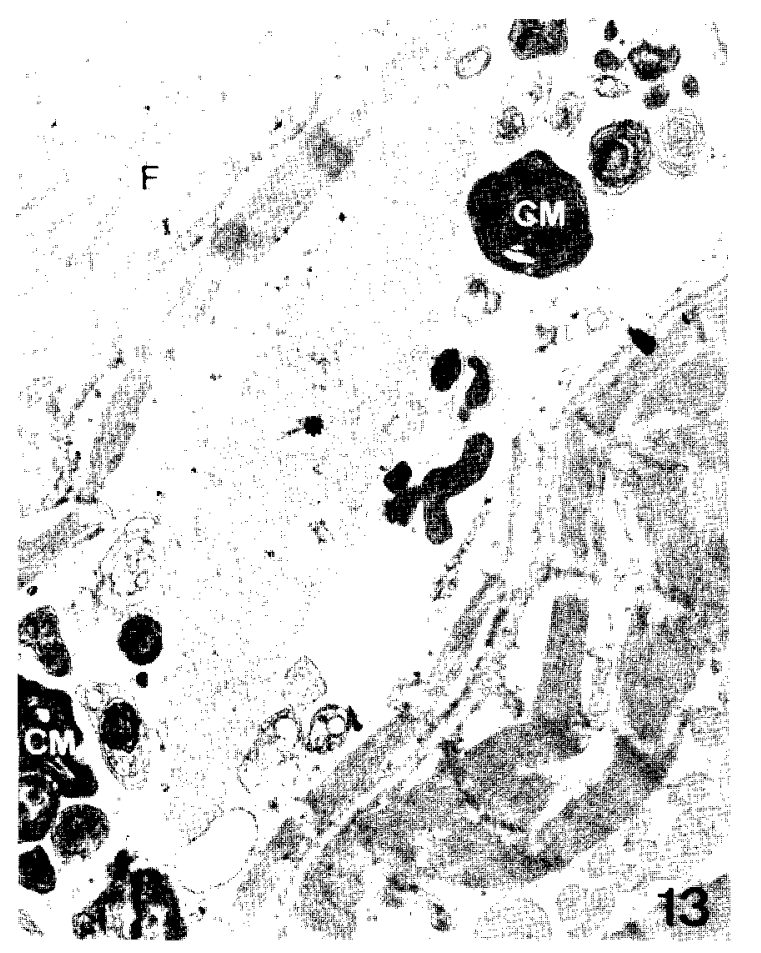

Figura 13 - EM: Miofibra atrófica com lise de miofilamentos (*) egrande número de corpos mielínicos (CM). Fibrose intersticial (F). 10560x.

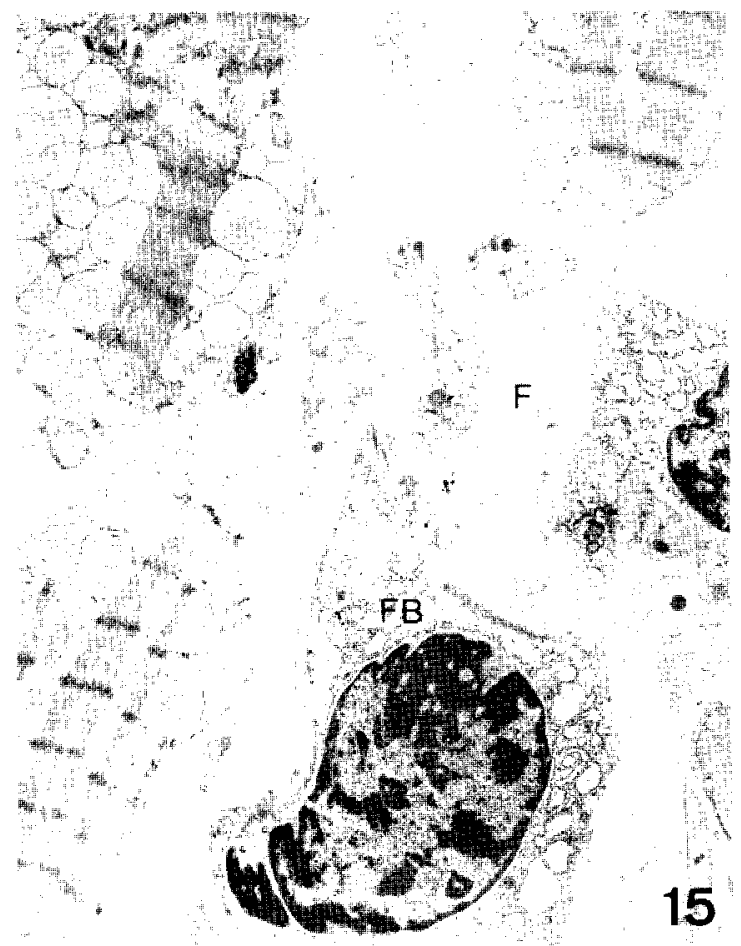

Figura 15-EM: Fibrose intersticial (F). Fibroblastos ativados (FB). 5200x.

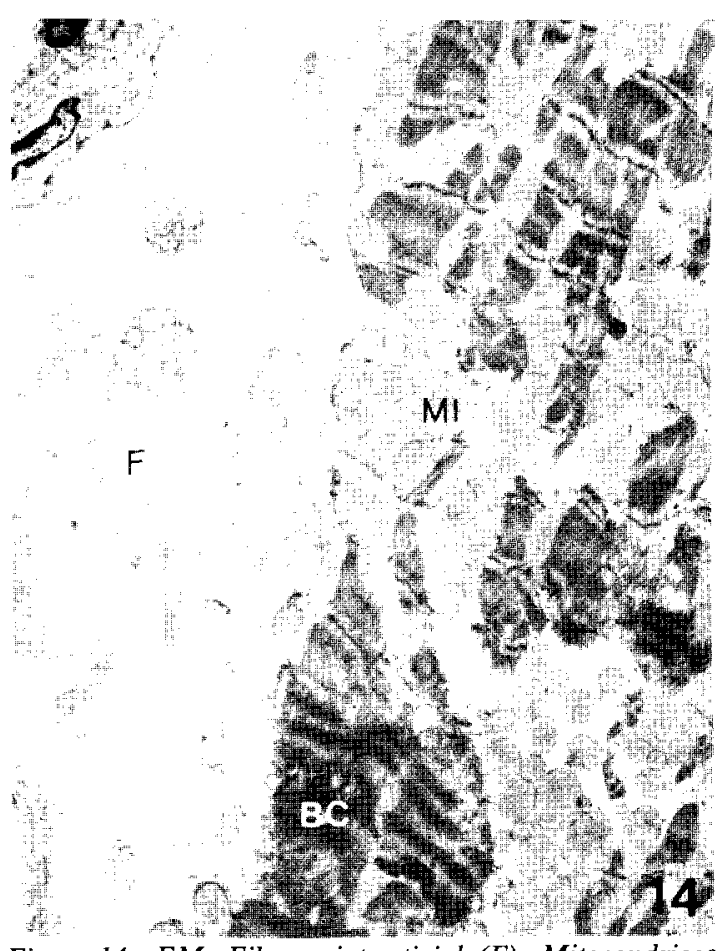

Figura 14-EM: Fibrose intersticial $(F)$. Mitocondriose (MI). Bandas de contratura (BC). 5200x.

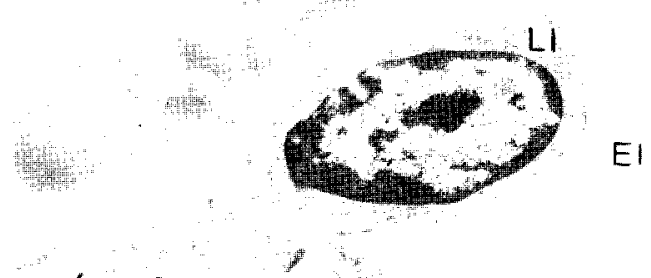

ti

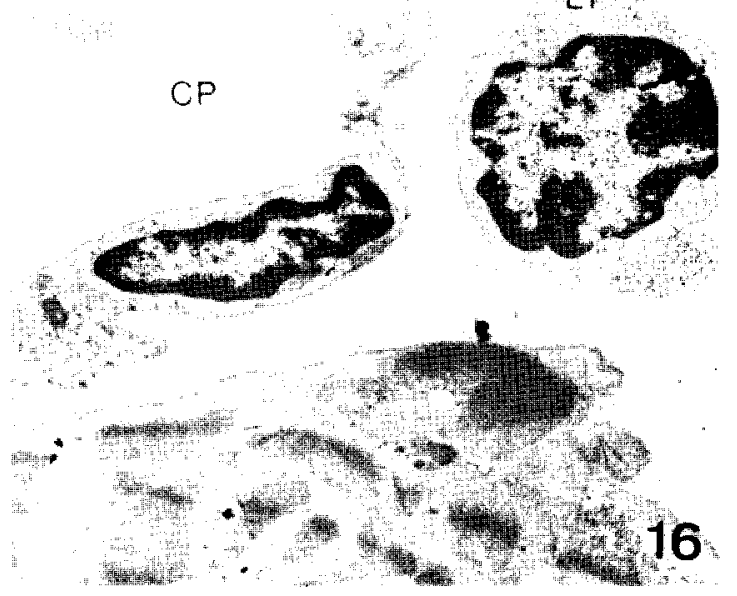

Figura 16-EM: Alargamento do espaço intersticial (EI), onde se nota microfibrilas e células mononucleares (linfócitos) (LI). CP, capilar. 7000x. 
Figueiredo $F$, Rossi MA, Santos RR. Evoluçào da cardiopatia experimentalmente induzida em coelhos infectados com Trypanosoma cruzi Revista da Sociedade Brasileira de Medicina Tropical 18: 133-141, Jul-Set, 1985

\section{DISCUSSÃO}

$\mathrm{Na}$ fase aguda da doença de Chagas no homem os parasitos podem ser detectados no sangue periférico através de métodos diretos e/ou do xenodiagnóstico. Posteriormente surgem os anticorpos especificos contra T. cruzi. Do ponto de vista patológico o coração pode estar discretamente aumentado de tamanho, com aumento de peso e dilatação de câmaras. Microscopicamente observa-se uma miocardite caracterizada por focos de necrose miocitolitica e de degeneração de miofibras, infiltrado inflamatório predominantemente mononuclear, discreta fibrose intersticial e fibras miocárdicas contendo pseudocistos parasitários. $\mathrm{Na}$ fase crônica os parasitos são dificilmente encontrados no sangue periférico, enquanto as provas sorológicas demonstram elevados títulos de anticorpos humorais especificos. Usualmente os corações apresentam-se com forma globular, hipertrofiados e com dilatação de todas as câmaras. Outras vezes apresentam-se normais na forma e no tamanho. Abaulamento do cone da pulmonar é quase sempre evidente. A lesão mais característica é o adelgaçamento e a protusão da região apical, particularmente do ventrículo esquerdo, encontada em cerca de $50-60 \%$ dos casos, usualmente denominada de aneurisma de ponta. Microscopicamente observam-se áreas focais de necrose miocitolítica e degeneração, com resposta inflamatória composta de células mononucleares com coincidente fibrose intersticial e ocasionais miofibras contendo pseudocistos parasitários. Lesões do sistema nervoso autônomo e do sistema de condução têm também sido descritas. As alterações patológicas que ocorrem na fase latente são muito pouco conhecidas $^{2} 613$.

Os nossos resultados mostram que o coelho é um animal susceptivel à infecção experimental com T. cruzi, corroborando resultados anteriores 182425 . $\mathrm{Na}$ fase aguda apresentam baixos níveis de parasitemia, demonstráveis através do xenodiagnóstico. A baixa parasiternia está de acordo com o relato na doença humana, na qual, em muitos casos, mesmo na fase aguda, o exame direto demonstra poucos parasi$\operatorname{tos}^{1714}$, sendo muitas vezes necessária a utilização de métodos de enriquecimento ou mesmo do xenodiagnóstico para a confirmação parasitológica 26 . Além disso, abservamos no curso da infecção o aparecimento de anticorpos humorais especificos contra $T$. cruzi. Esses dados estão de acordo com a literatura, muito semelhantes aos verificados na doença humana, caracterizada por altos niveis de anticorpos, predominantemente da classe IgM na fase aguda e da classe IgG na fase crônica ${ }^{6}$.

Com relação à anatomia patológica do coração nossos resultados demonstram que coelhos experi- mentalmente infectados desenvolvem muitos aspectos da doença cardíaca no homem. $\mathrm{Na}$ fase inicial as alterações cardiacas são caracterizadas macroscopicamente por cardiomegalia discreta, com dilatação de câmaras direitas, e microscopicamente por miocardite focal pouco acentuada. Na fase cronica a sindrome cardíaca é caracterizada macroscopicamente por cardiomegalia moderada ou acentuada com hipertrofia e dilatação de câmaras, e adelgaçamento da ponta (aneurisma apical), predominantemente do ventriculo esquerdo; microscopicamente, por miocardite focal intensa, com áreas de necrose miocitolitica e degeneração de miocélulas, miofibras atróficas ao lado de outras hipertróficas, associadas a um fenómeno inflamatório, predominantemente composto de linfócitos, e fibrose intersticial. Observações anteriores 1825 mostraram, em coelhos cronicamente infectados com $T$. cruzi, alterações eletrocardiográficas e anatomopatológicas muito semelhantes às descritas no homem e às do presente estudo. Os nosso achados ultra-estruturais são muito semelhantes àqueles observados na cardiopatia chagásica crônica humana 1522 . Todavia, essas alterações morfológicas não são específicas, desde que alterações idênticas têm sido descritas em várias formas de doença cardíaca, tais como cardiomiopatia congestiva e valvulopatia aórtica $^{15}$.

O emprego de modelos experimentais animais tem sido importante para o estudo dos possiveis mecanismos envolvidos na patogênese da cardiopatia chagásica ${ }^{2}$. Mecanismos imunológicos têm sido implicados 8202324 . Lesão de neurônios autonômicos sido postulada como um mecanismo patogenético alternativo ${ }^{13}$. A participação de mecanismos autoimunes se fundamenta na miocardite caracterizada por um infiltrado de células mononucleares, observada nas fases aguda e crônica 23 . A reação inflamatória se assemelha às lesões de outras doenças de hipersensibilidade. O mecanismo de lise tecidual seria dependente da sensibilização a antigenos parasitários 1920 ou por reatividade cruzada entre o parasito e componentes teciduais 232427 e mediado por células imunocompetentes capazes de induzir células efetoras de lesão. $O$ estudo microscópico do miocárdio de coelhos infectados mostrou um infiltrado inflamatório mononuclear associado a lesões de miofibras, tanto na fase aguda como na fase crònica. Também caracterizamos por meio de microscopia óptica e eletrônica alteraçōes miocelulares muito semelhantes à necrose não-coronarigênica observada em um grande número de doenças cardiacas no homem. Uma forma semelhante de lesão focal tem sido observada experimentalmente ${ }^{11}$ e clinicamente ${ }^{3}$ na isquemia transitória do miocárdio. Esses fatos, associados ao caráter focal da lesão miocárdica, constituem evidências indiretas da participa- 
Figueiredo $F$, Rossi MA, Santos RR. Evolução da cardiopatia experimentalmente induzida em coelhos infectados com Trypanosoma cruzi Revista da Sociedade Brasileira de Medicina Tropical 18: 133-141, Jul-Set, 1985

ção da microcirculação na gênese das alterações miocárdicas no presente modelo. Recentemente, tem sido sugerido que a microcirculação poderia estar implicada na patogênese da cardiopatia chagásica 21 . Desse modo, o substrato morfológico da cardiopatia experimental induzida em coelhoc inoculados com a cepa Colômbia de $T$. cruzi sugere que no seu determinismo poderiam estar envolvidos mecanismos imunológicos e isquêmicos.

Em resumo, coelhos jovens experimentalmente infectados com $T$. cruzi desenvolvem alterações patológicas do coração, macro e microscópicas, além de caracteristicas parasitológicas e imunológicas, muito semelhantes às observadas na doença de Chagas humana, tanto na fase aguda como na fase crónica. Desse modo, devido à reprodução de aspectos fundamentais da doença cardiaca em um tempo relativamente curto, à simplicidade, à disponibilidade para múltiplos pesquisadores e ao baixo custo, esse modelo parece ser adequado para estudos sobre mecanismos, patologia e tratamento da cardiopatia chagásica.

\section{SUMMARY}

Male and female outbred young rabbits ( $1-2$ months of age) inoculated with trypomastigote forms of the Colombia strain of $\mathrm{T}$. cruzi have been shown to develop cardiac pathologic changes, besides parasitological and immunological features, very similar to those observed in both acute and chronic phases of Chagas' disease in man. In the acute phase the cardiac syndrome is characterized grossly by slight cardiomegaly, with dilatation of the right chambers and microscopically by discrete focal myocarditis: in the chronic phase, by moderate or marked cardiomegaly, with hypertrophy and dilatation of all chambers, and thinning of the ventricular apex (apical aneurysm), particularly of the left ventricle, and striking focal myocarditis, with areas of myocytolytic necrosis and degeneration of myofibers, with concurrent inflammatory response, predominantly composed of lymphocytes, and interstitial fibrosis. The accurate reproduction of the cardiac disease in a relatively short period, the simplicity, availability and long survival of the animal, and the low costs make this animal model suitable for studies on pathology and treatment of chagasic cardiopathy.

Key words: Trypanosoma cruzi Rabbit. Chagasic cardiopathy. Chagas' disease. Experimental model.

\section{AGRADECIMENTOS}

Os autores agradecem às Sras Maria M.O.Rossi, Maria Helena L.N. Gomes e aos Srs. Carlos Kipnis e
Ivo Mazucato pela excelente assistência técnica, e à Srta Dina B. Pelizaro pelo trabalho datilografico.

\section{REFERÊNCIAS BIBLIOGRÁFICAS}

1. Amato-Neto V. Contribuição ao estudo da forma aguda da doença de Chagas. Tese de livre-docência. Faculdade de Medicina de Ribeirão Preto, USP, Ribeirão Preto, 1958.

2. Andrade Z, Andrade SG. Patologia. In: Brener Z, Andrade $\mathrm{Z}$ (ed). Trypanosoma cruzi e Doença de Chagas. Editora Guanabara Koogan, Rio de Janeiro, p. 199-248, 1979.

3. Bulkley BH, Hutchins GM. Myorcadial consequences of coronary artery bypass graft surgery: the paradox of necrosis in areas of revascularization, 56: 906-913, 1977.

4. Camargo ME. Fluorescent antibody test for serodiagnosis of American trypanosomiasis. Technical modification employing preserved culture forms of Trypanosoma cruzi in a slide test. Revista do Instituto de Medicina Tropical de São Paulo 8: 277-234, 1966.

5. Camargo ME, Hoshino S, Siqueira GRV. Hemagglutination with preserved sensitized cells: practical test for routine serologic diagnosis of American trypanosomiasis. Revista do Instituto de Medicina Tropical de São Paulo 15: 81-85, 1973.

6. Camargo ME, Takeda GKF. Diagnóstico de laboratório. In: Brener Z, Andrade Z (ed) Trypanosoma cruzi e Doença de Chagas. Editora Guanabara Koogan, Rio de Janeiro, p. 175-198, 1979.

7. Chagas C. Tripanozomiase americana: forma aguda da moléstia. Memórias do Instituto Oswaldo Cruz 8: 37-60, 1916.

8. Cossio PM, Laguens RP, Diez C, Szarfman A, Segal A, Araña RM. Chagasic cardiopaty: antibodies reacting with plasma membrane of striated muscle and endothelial cells. Circulation 50: 1252-1259, 1974.

9. Federici EE, Abelmann, WH, Neva FA. Chronic progressive myocarditis and myositis in $\mathrm{C} 3 \mathrm{H}$ mice infected with Trypanosoma cruzi. American Journal of Tropical Medicine and Hygiene 13: 272-280, 1964.

10. Figueiredo $F$. Infecção experimental de coelhos com Trypanosoma cruzi: aspectos de parasitologia, imunologia e patologia. Tese de mestrado. Faculdade de Medicina de Ribeirão Preto, USP, Ribeirão Preto, 1984.

11. Jennings RB, Ganote CE. Structural changes in myocardium during acute ischemia. Circulation Research 35 (Supl. III): 156-172, 1974

12. Jörg ME. Tripanosomiasis cruzi: anarquía angiotopográfica por descapilarización mesenquimorreactiva, co- 
Figueiredo F, Rossi MA, Santos RR. Evoluçào da cardiopatia experimentalmente induzida em coelhos infectados com Trypanosoma cruzi. Revista da Sociedade Brasileira de Medicina Tropical 18: 133-141, Jul-Set, 1985

factor patogénico de la miocardiopatia crónica. Prensa Médica Argentina 61: 94-106, 1974.

13. Köberle F. Chagas' disease and Chagas' syndromes: the pathology of American trypanosomiasis. In: Dawes B (ed) Advances in Parasitology, vol. 6, Academic Press, London, p. 63-116, 1968.

14. Mazza S, Benitez C. Segundo caso de forma aguda de enfermedad de Chagas comprobado en Corrientes. Misión de Estudos de Patologia Regional Argentina 28: 13-22, 1936.

15. Palacios-Prü E, Carrasco H, Scorza C, Spinoza R. Ultraestructura miocárdica en la enfermedad miocárdica de Chagas. Diagnóstico diferencial con la miocardiopatía dilatada o congestina y con las miocardiopatías arrítmicas. Revista Latino-Americana de Cardiología 3: 115-137, 1982.

16. Prata A. Chagas' heart disease. Introduction. Cardiologia 52: 79-81, 1968.

17. Puigbo J. Chagas' heart disease. Clinical aspects. Cardiologia 52: 91-96, 1968.

18. Ramirez LE, Vargas M, Dias JCP, Brener Z. Histopathological and electrocardiographic studies in rabbits experimentally inoculated with Trypanosoma cruzi. In: Resumos da X Reunião Anual de Pesquisa Básica em Doença de Chagas, Caxambu; p. 334, 1983.

19. Ribeiro-dos-Santos R, Rassi A, Köberle F. Chagas' disease. Antibiotics and Chemotherapeutics 30: 115134,1981 .

20. Ribeiro-dos-Santos R, Rossi MA. Imunopatologia da cardiopatia chagásica. In: Cançado JR, Chuster $\mathbf{M}$ (ed) Cardiopatia Chagásica, 1985 (no prelo).

21. Rossi MA, Gonçalves S, Santos RR. Experimental Trypanosoma cruzi cardiomyopathy in BALB/c mice: the potential role of intravascular platelet aggregation in its genesis. American Journal of Pathology 114: 209$216,1984$.

22. Tafuri WL, Maria TA, Lopes ER, Chapadeiro ER. Microscopia eletrônica do miocárdio na tripanosomíase cruzi humana. Revista do Instituto de Medicina Tropical de São Paulo 15: 347-370, 1973.

23. Teixeira ARL. Patogênia da doença de Chagas. Jornal Brasileiro de Medicina 38: 23-33, 1980.

24. Teixeira ARL, Teixeira L, Santos-Buch CA. The immunology of experimental Chagas' disease. IV. The production of lesions in rabbits similar to those of chronic Chagas' disease in man. American Journal of Pathology 80: 163-177, 1975.

25. Teixeira ARL, Figueiredo F, Rezende-Filho J, Macedo V. Chagas' disease: a clinical, parasitological, immunological, and pathological study in rabbits. American Journal of Tropical Medicine and Hygiene 32: 258-272, 1983.

26. Teixeira MGLC. Doença de Chagas. Estudo da forma aguida inaparente. Tese de mestrado. Faculdade de Medicina da Universidade Federal do Rio de Janeiro, Rio de Janeiro, 1977.

27. Teixeira ML, Rezende Filho J, Figueiredo F, Teixeira ARL. Chagas' dise ase: selective affinity and cytotoxicity of Trypanosoma cruzi - immune lymphocytes to parasympathetic ganglion cells. Memórias do Instituto Oswaldo Cruz 75: 33-45, 1980.

28. Torres CM. Miocitólise e fibrose do miocárdio na doença de Chagas. Memórias do Instituto Oswaldo Cruz 58: $161-182,1960$.

29. World Health Organization Technical Report Series 697. Chagas' disease. In: Cardiomyopathies. Report of a WHO Expert Comittee. World Health Organization, Geneva, p. 50-55, 1984. 